\title{
A experiência agrária em Goiás no governo Mauro Borges: sentido e desdobramentos
}

\author{
Tereza Cristina Favaro \\ Universidade Federal de Goiás (UFG)
}

\section{A experiência agrária em Goiás no governo Mauro Borges: sentido e desdobramentos}

Resumo: O artigo faz um resgate histórico da experiência agrária ocorrida em Goiás no governo Mauro Borges (1961-1964), sobretudo, o projeto de colonização. Inicialmente, em linhas gerais, faz uma apresentação do governo de Goiás com uma breve contextualização da realidade agrária no plano nacional e local. Finalmente, explora as evidências de como o controle social foi posto em prática sob o argumento da modernização da agricultura, a busca por conter a organização e a mobilização camponesa, além da ação dos comunistas. Palavras-chave: Política agrária. Modernização. Capitalismo.

The Agrarian Experience in Goiás under Governor Mauro Borges: Its meaning and consequences Abstract: This article conducts a historic review of the agrarian experience in Goiás during the government of Mauro Borges (18611964), particularly the land settlement project. It first presents the government of Goiás in general lines with a brief contextualization of the agrarian reality on the national and local levels. It then explores the evidences of how social control was placed in practice under the argument of modernization of agriculture, in an effort to contain the organization and mobilization of farm workers, as well as the action of communists.

Keywords: Agrarian policy. Modernization. Capitalism. 


\section{Introdução}

Mauro Borges Teixeira, governador do estado de Goiás no período 1961-1964, soube tirar proveito dos fatores objetivamente favoráveis e que apontavam na direção de um projeto político inovador. Sem expressão e vivência política, beneficiou-se da condição de filho do fundador de Goiânia, capital do estado, Pedro Ludovico Teixeira - cacique da política em Goiás que comandava o Partido Social Democrático (PSD) de maneira caudilhesca. Militar, graduado pela Escola de Estado-Maior do Exército, com especialização em Transportes, Mauro Borges distinguiu-se como defensor da ordem legal, das garantias institucionais, das ideias nacionalistas e da rejeição ao comunismo, atitudes disseminadas pelos militares brasileiros após 1935, acentuadas a partir de 1947, com o advento da Guerra Fria, e que ganharam corpo com o golpe de 1964. Esses elementos só podem ser analisados dentro de um plano maior. No início de seu mandato de governador, pelo PSD, Mauro Borges lançou o Plano de Desenvolvimento Econômico, denominado Plano Mauro Borges (MB), fundamentado e empreendido por técnicos da Fundação Getúlio Vargas, do Rio de Janeiro, e estruturado com base no modelo de Fayol: Prever, Organizar, Planejar e Executar, com um arcabouço institucional centrado no planejamento intervencionista. Planejamento que, naquela conjuntura, emergia na busca pela eficiência e racionalidade, sobretudo, na viabilização de acordos de cooperação e assistência técnico-financeira de interesse dos estados brasileiros e do governo federal. Exemplo era o programa Aliança para o Progresso ${ }^{1}$, cuja contrapartida estava na adoção de programas de investimentos e de reformas orientados pelos princípios do planejamento.

No Plano MB, fica claro o objetivo do aperfeiçoamento das Condições Gerais de Produção (CGP), referidas por Bernardo (2009) como mecanismos necessários e indispensáveis à organização geral e ao desenvolvimento do capitalismo, uma vez que envolviam a infraestrutura material, tecnológica, sanitária, social, cultural e repressiva necessária, traduzida na abertura e pavimentação de estradas, na ampliação dos meios de transporte, no abastecimento de água, na expansão da iluminação pública e da comunicação, além da construção de escolas, hospitais, postos de saúde, escolas profissionalizantes e creches. Dessa maneira, o plano buscava adequar o estado ao novo padrão de acumulação em curso no país. Houve um esforço por parte de Mauro Borges em lançar mão de um perfil racional no modo de conduzir os negócios públicos estaduais, sem, contudo, alijar as práticas clientelistas e os interesses pessoais no cotidiano institucional.

A adoção de um programa marcado por forte estatismo, no qual a questão agrária tinha um peso importante, acentuou as divergências entre Mauro Borges e os proprietários rurais. Os fazendeiros se mostravam incomodados com a condição de subordinados à administração e, assim, traziam à tona outras questões, além do item fundiário: "Aparece uma retomada da sociedade rural, dos valores tradicionais, momentaneamente eclipsados pela modernidade que o país e o estado de Goiás buscavam no projeto desenvolvimentista" (SOUZA, 1990, p. 86). Por seu lado, o governador tentava equilibrar-se no apoio de setores do meio rural e, ao mesmo tempo, de parte da esquerda, que inclusive participava de sua gestão.

A conjuntura nacional do início da década de 1960, na qual se inseriu a experiência administrativa de Mauro Borges, expressava um cenário político pressionado por turbulências na busca do desenvolvimento econômico. Muitos eram os enfrentamentos na correlação de forças diante do rápido processo de industrialização, de introdução do capital estrangeiro e das multinacionais, o que resultou no crescimento da população urbana e também na ampliação da participação política das classes populares e no fortalecimento do movimento operário e dos trabalhadores do campo, como as ligas camponesas em luta pela posse da terra ${ }^{2}$.

Em Goiás, foi significativo o crescimento da organização camponesa. Em contraposição, os latifundiários criaram a Sociedade Goiana de Pecuária e Agricultura (SGPA), na tentativa de impedir as mudanças na estrutura fundiária e nas relações de trabalho no campo. Os acontecimentos na região de Trombas e Formoso chegaram à imprensa goiana e nacional, provocando debate sobre o assunto. A mobilização preocupava os setores conservadores da sociedade em âmbito nacional e local, e o próprio Mauro Borges.

\section{O homem certo para o lugar certo}

Na eleição, Mauro Borges não recebeu o apoio formal da Associação de Lavradores de Trombas e Formoso nem do Partido Comunista Brasileiro (PCB), o que Pereira (2006) considerou importante para a vitória maurista, tendo em vista a formação de Goiás, assentada em bases conservadoras, reacionárias e oligarcas. Contudo, o futuro governador recebeu apoio de parcela dos camponeses, ao assumir, na plataforma política apresentada, o compromisso de regularizar a posse de terras no estado.

A dinamização da região e os conflitos sociais no campo sinalizavam a Mauro Borges a necessidade imperiosa de "reorganização do espaço agrário goiano" (ESTEVES, 2011, p. 56), consubstanciado nas CGP. O discurso de posse foi emblemático, em defesa "da elevação do padrão de vida do povo goiano", com o cumpri- 
mento do artigo 147 da Constituição estadual - "O uso da propriedade deve ser condicionado ao bem-estar social" - e do artigo 141 - "promover a justa distribuição da propriedade, com igual oportunidade para todos".

O estado de Goiás registrava urbanização crescente, associada à ostensiva presença do latifúndio ${ }^{3}$, com tudo o que ele representava. De acordo com o censo de 1950, existiam, em Goiás, 63.736 estabelecimentos agrícolas, ocupando área de $245.881 \mathrm{~km}^{2}$, equivalente a $40 \%$ da área do estado. Note-se quão grande era a área destinada à pecuária e de terras incultas e improdutivas, mantenedoras do latifúndio, o que sustentava a luta dos movimentos por terra para quem nela trabalhava. O cenário favorável à agropecuária resultou nas políticas colocadas em marcha pelos governos das diferentes esferas de poder. Desde a década de 1950, a região Centro-Oeste - fronteira do capital -, e nela Goiás, experimentou um acelerado crescimento econômico em razão da agricultura comercial, em especial das culturas de grãos, e da pecuária, o que exigia um contínuo aumento da produtividade. Todavia, foram mudanças que não resultaram em melhorias reais para a população em geral. Isso porque o poder público, como agente da expansão da fronteira, incentivava a migração dos trabalhadores para regiões longínquas do país, de onde a agricultura empresarial, por debilidade de infraestrutura - comunicação, estradas, mão de obra - não se apropriou. Ao incentivar o deslocamento dos trabalhadores para tais regiões, o Estado respaldou o capital e o latifúndio com as políticas adotadas e a presença de relações sociais do passado, reatualizadas enquanto exploração do capital. Assim, legitimando que, na fronteira, o outro é degradado, para, desse modo, "viabilizar a existência de quem o domina, subjuga e explora", afirma Martins (1997, p. 11).

Ao longo dos anos, o setor agrário goiano foi se adaptando à conjuntura socioeconômica nacional, passando por especialização e reorganização para atender o mercado, sem que "isso significasse necessariamente mudanças na estrutura de produção" (BORGES, 2005, p. 127). Ao contrário, o padrão de especialização adotado pela agropecuária robusteceu o latifúndio como forma de propriedade e reforçou a tradicional estrutura de produção no campo a serviço do mercado, a qual "se definia como reserva de acumulação primitiva para a expansão do capital" (BORGES, 2005, p. 128) mediante o rebaixamento dos preços dos bens primários e, consequentemente, o aviltamento da remuneração da mão de obra. Isso garantia ao capital e ao proprietário de terras extorquirem ao máximo o sobretrabalho (BORGES, 2005, p. 12). A manutenção do modelo e do latifúndio atendia também a interesses políticos. Desse modo, em Goiás "a natureza social e ideológica do poder emergente em 1930 contribuiu para manter inalterada a estrutura fundiária e bloqueou qualquer ação política no sentido de transformá-la" (BORGES, 2005, p 129). A demonstração de poder pessoal centrado na figura do fazendeiro, contribuía para a subsistência do coronelismo, com manipulação da máquina pública para benefícios privados, em troca de votos ou de qualquer outro tipo de apoio que necessitasse o chefe político (LEAL, 2012; CARVALHO, 1997), reforçando, desse modo, que a prática do coronelismo caminhava pari passu com o clientelismo e com o personalismo no exercício do poder político. Aliás, com resquícios até os dias atuais.

A estrutura fundiária brasileira foi construída historicamente, com raízes no sistema sesmarial, por meio de estatuto jurídico transportado de Portugal para a colônia, para regulamentar a concessão de terras. O Estado português doava grandes glebas a serem exploradas pelos senhores de escravos, conforme os interesses da empresa colonial e da metrópole. Abolidas as sesmarias, o Brasil, até meados do século 19, fícou sem instrumento jurídico para normalizar a propriedade fundiária. Nesse lapso de tempo, quem tinha força e influência política apoderava-se livremente das terras devolutas. A Lei de Terras, sancionada em 1850, institucionalizou a propriedade da terra no país, legalizando as sesmarias e a posse de grandes extensões de terras como propriedade privada. São elementos que contribuíram decisivamente para a estrutura agrária desigual, presente desde sempre no Brasil, com particularidade tão perversa e marcante no campo. Afirma Prado Jr. (1979, p. 48): "a colonização brasileira, e a ocupação progressiva do território que formaria nosso país, constituiu sempre, desde o início, e ainda é essencialmente assim nos dias que correm um empreendimento mercantil".

Sobre os latifúndios, pesa a existência dos altos lucros auferidos em contraste com os baixos salários pagos a quem neles trabalha, inclusive sob contratações não formalizadas. Essa realidade acarretou o aumento da taxa de exploração da força de trabalho e a deterioração das condições de vida dos trabalhadores rurais, sua consequente migração para as periferias das grandes cidades, onde se submetendo a baixos salários, à informalidade, à precarização das moradias, dentre outras situações desfavoráveis. Para Bruno (1995, p. 19), os "males do latifúndio não se restringiam ao rural e seriam responsáveis pela não qualificação da mão de obra, a favelização, o empreguismo e o peleguismo". Além disso, sucumbindo-se a uma existência miserável nas cidades e sem uma presença do Estado que viesse assegurar melhores condições de vida, essa população tornou-se vulnerável ao crime organizado e às consequências que isso representa.

$\mathrm{O}$ alcance do Plano MB não se contrapunha aos interesses dos grupos dominantes, contrários a qualquer alteração da ordem ou da estrutura agrária. O latifúndio é sinônimo de poder. Em si, o Plano almejava a modernização do campo com incentivo à agropecuária empresarial, a fim de atender às demandas do mercado externo e 
interno. Ocupava-se, ainda, da permanência do homem no campo, por meio da política de colonização, com proposta de melhoria econômica, mediante acesso às CGP, traduzidas em escolas rurais, ensino técnico, fazendas-modelo e capacitação em novas técnicas/práticas agrícolas e de manejo do solo. O cerne da questão era levar modernidade e prosperidade ao trabalhador do campo como resultado da modernização e do aumento da produção. Importava articular estratégia de modernização com a racionalização, na tentativa de superar o atraso, aumentar a produtividade sem colocar em risco os interesses dos latifundiários e, ao mesmo tempo, contrapor-se à organização camponesa na luta por um pedaço de terra e à presença comunista no campo.

O chão histórico e político de transformação econômico-social na região trouxe o avanço capitalista no campo, sobretudo na segunda metade dos anos 1950 e intensificado no começo dos anos 1960, com a construção de Brasília. Nesse contexto, em consonância com o Plano MB, o governo maurista contratou assessoria do Escritório Técnico Paulo de Assis Ribeiro (ETPAR), para elaborar estudo referente à situação agrária de Goiás ${ }^{4}$. A atuação política desse escritório, com sua "elite técnica", assegurava a formulação de "projetos privados de classe a serem universalizados mediante conversão em políticas públicas por agências estatais" (ESTEVES, 2011, p. 16). Constitui-se reforçando a iniciativa de implantar uma agricultura em moldes capitalistas e, no entendimento de Silva (1981, p. 45), "o sentido último do desenvolvimento do capitalismo no campo é a própria industrialização da agricultura". A centralidade assumida pela questão agrária na gestão maurista alterou a correlação de forças dentro do aparelho do estado e nas políticas públicas perpetradas em Goiás, impulsionando o direcionamento de mais recursos para o setor, inclusive com verba externa, como a do programa estadunidense Aliança para o Progresso (Corpos da Paz e o Alimento para a Paz). Com isso, a agropecuária ganhou maior atuação dos escritórios tecnoempresariais e dos seus gestores/tecnocratas.

As estratégias de modernização sob a gestão estatal não colocavam em risco os interesses dos latifundiários, mas se contrapunham à ofensiva camponesa por meio de uma colonização em bases cooperativistas, estratégia que se aproximava, em parte, da experiência adotada em 1941 pelo governo estadonovista de Vargas Marcha para o oeste -, com a criação da Colônia Agrária Nacional de Goiás, no Vale de São Patrício (município de Jaraguá), dentro da proposta de ocupação e interiorização do país. Constituiu-se na primeira experiência de colonização planejada em Goiás, atraiu migrantes e assegurou a ampliação da força de trabalho destinada à agricultura (CAMPOS, 2009). A articulação colocada em prática para a operacionalização das diretrizes apontadas pelo ETPAR não deixou dúvidas em relação ao empenho da gestão maurista na proposta de colonização. Contou-se com assessoria de técnicos franceses, na indicação do local, e de israelenses, na organização das cooperativas. O Serviço Geográfico do Exército delimitou as áreas onde seriam instalados os combinados, com base em levantamentos aerofotogramétricos da Força Aérea Brasileira (FAB). Por outro lado, o Departamento de Psicologia e Psicotécnica da Academia Militar das Agulhas Negras (Aman) fez a seleção dos colonos, utilizando testes psicológicos, uma inspiração taylorista como estratégia para reduzir a ocorrência de desajustamento no ambiente de trabalho e aumentar a produtividade e a satisfação dos trabalhadores.

\section{Os Combinados Agrourbanos: do sonho camponês à realidade do agrarismo ipesiano}

As diretrizes apontadas pelo ETPAR para o espaço agrário goiano indicaram a mecanização da agricultura e o fomento à produção capitalista para o sul do estado de Goiás, próximo à fronteira com a região Sudeste do Brasil, e a retomada da política de colonização agrícola, com a criação de novos núcleos pela ocupação de terras devolutas situadas no norte do estado. O plano resumia boa parte da cultura técnica e das preocupações com a ordem político-social para aquela conjuntura, ao mesmo tempo em que espelhava princípios pautados pelo Ipes ${ }^{5}$ para a reforma agrária. As forças conservadoras brasileiras utilizaram a reforma agrária como pretexto para travar uma guerra psicológica de diferentes formas e manifestações no combate ao comunismo. Para tanto, contavam com o apoio dos Estados Unidos, que pressionavam o Brasil a implantar uma reforma dentro dos limites aceitáveis, temerosos da influência da revolução cubana na América Latina. O modelo do agrarismo ipesiano afinado com as diretrizes emanadas da encíclica papal Mater et Magistra - previa a criação de uma classe média rural, em respeito à propriedade privada, ou seja, à preservação da estrutura fundiária. Para isso, buscava orientar-se em projetos de assistência técnica, em planos de colonização e em iniciativas de políticas agrícolas voltadas à promoção do desenvolvimento agropecuário das regiões brasileiras. Outro elemento presente, de inspiração ipesiana, é a Justiça Agrária, para solucionar demandas específicas das relações sociais oriundas do mundo rural, vistas como complexas, por abarcarem "várias formas de contrato de trabalho e relações de interdependência entre trabalhadores rurais e proprietários de terras" (ESTEVES, 2011, p. 238).

Na condução da política agrária maurista, por indicação do ETPAR, foi criado o Instituto de Desenvolvimento Agrário de Goiás (Idago), agência responsável pela promoção das transformações técnicas, econômicas, estruturais e institucionais da agropecuária goiana, para "cumprir a finalidade de promover o desenvolvi- 
mento econômico e social de forma equilibrada e democrática" (GOIÁS, 1963c, n.p). A presidência do instituto foi ocupada inicialmente, por Archimedes Pereira $\mathrm{Lima}^{6}$, e coube a um militar da elite do exército, o coronel Petrônio Maia Vieira do Nascimento Sá, a organização, o comando e o controle do referido órgão. Por meio dele, buscou-se garantir as CGP necessárias à consolidação do projeto político-ideológico, para assegurar o progresso e a modernização do setor, com ênfase na técnica e na defesa da ordem pública, esta entendida como controle das agitações no campo e combate ao inimigo da nação: o comunismo.

$\mathrm{Se}$, por um lado, Mauro Borges incorporava algumas demandas populares como estratégia para legitimar suas ações, por outro, cerceava a participação ao pairar qualquer ameaça à ordem instituída, inclusive com o uso a força policial. Em suas palavras:

quando houve uma invasão organizada na fazenda São Carlos [o governo] mandou para lá a polícia inteira, inclusive foi o coronel Joel [José Joel Marcos] pessoalmente e reprimiu com energia e em pouco tempo limpou toda a área [...] não há meio termo [...] é compreender o problema até onde vai o justo direito dele e onde ultrapassa esse direito. [...] Existe muito pouca gente que pensa em ajudar posseiros, mas absolutamente não concordamos em que se faça invasão de propriedade privada (GOIÁS, 1962a, p.11).

O ETPAR assumiu a responsabilidade pela sistematização das atividades de funcionamento e pela filosofia de ação do novo órgão e, assim, designou alguns técnicos para atuarem em Goiânia junto ao Idago. Por essa via, foram idealizados os Combinados Agrourbanos (CAUs), identificados como "novo procedimento científico", com base nas experiências de Israel com o cooperativismo ${ }^{7}$, no intuito de atender às necessidades do campesinato e superar as condições de subdesenvolvimento das regiões do estado de Goiás. Para seus idealizadores, os Combinados deveriam promover a "integração regional e nacional de comunidades segregadas" e ser um elemento harmônico dentro das particularidades e características do nosso meio físico e rural (TEIXEIRA, 2006, p. 64). Os CAUs eram constituídos por núcleos coloniais e a cada um era destinada uma vila - Rurópolis -, área para 200 casas residenciais, com água e eletricidade para as famílias de colonos, e também para a construção de escola primária, posto médico, cooperativas de produção de insumo, centro social, quadra de esporte e templo religioso (GOIÁS, 1963c). A proposta inicial sinalizava para a criação de Combinados em três regiões: CAU1, no município de Arraias (o primeiro instalado); CAU2, no município de Tocantinópolis; e CAU3, no extremo norte goiano, hoje estado do Tocantins, em Araguacema. Alguns fatores foram preponderantes na escolha para a implantação dos CAUs, como: região longínqua e possibilidade de obter terras planas a preço baixo (GOIÁS, 1963c). O detalhamento do CAU e de seus objetivos estava expresso na Cartilha para o Combinado Agro-Urbano, produzida pelo Idago, que continha as regras de funcionamento e de comportamento a serem seguidas pelos colonos e familiares. Em cada Rurópolis haveria uma central para controle das contas e despesas das famílias, com advertência em caso de excederem nos gastos. O dia de trabalho dos agricultores não teria limite, "quanto mais horas trabalhar maior será o lucro". Para membros não agricultores, a jornada compreenderia 8 horas diárias (GOIÁS, 1963c, n.p.).

Sob o capitalismo, importa a fiscalização do comportamento no mundo do trabalho tanto quanto a vida privada, inclusive o "controle dos próprios processos psíquicos dos trabalhadores" (BERNARDO, 2009, p. 225), visto que o trabalhador debilitado psicologicamente pode ter seu rendimento comprometido. Por ser assim, tornava-se inegável a apropriação dos recursos necessários para atingir os fins, como demonstrado pelo major psicólogo Paulo da Costa Moura, ao priorizar a seleção orientada por princípios tayloristas. Dessa forma, almejava dispor dos melhores colonos, aqueles que se adaptassem ao trabalho racionalizado e se submetessem física e psicologicamente à lógica e ao tempo de trabalho estabelecido pelos gestores/tecnocratas para os Combinados:

Levados à região e já instalados nos combinados, [...] agora é verificar, a integração desses homens [...] sobretudo quando temos em vista que não vão fazer uma só atividade, mas começarão a viver uma nova vida mais digna mais humana, mais evoluída. É necessário vislumbrar e preparar integração social (GOIÁS, 1963a, p. 26).

Como se ambicionava reduzir as ocorrências de desajustamento no ambiente de trabalho e aumentar a produtividade e a satisfação dos trabalhadores, a primeira parte da seleção destinava-se à "avaliação da inteligência", e a segunda, à:

aptidão, [que] visava avaliar a [...] personalidade é aquilo que o indivíduo é, a sua integração dinâmica, é a maneira de ser, de se comportar habitualmente. Isso tem alta importância para as colônias do Idago. [...] Um indivíduo desajustado [...] seria, antes, um empecilho às colônias do Idago do que propriamente um elemento produtivo dessas colônias (GOIÁS, 1963a, p. 26). 
Em outras palavras, o major Paulo considerava a necessidade de seleção dos homens certos para distribuílos pelas várias atividades. Por essa via, "as informações profissionais [devem] servir como subsídio à direção técnica [...] tudo isso tem sido muito útil à direção do Idago, que pode manobrar com esses elementos à sua vontade" (GOIÁS, 1963a, p. 25-26). Todo esse trabalho seletivo era feito sob criteriosa avaliação médica:

inicialmente procuramos verificar no homem as suas condições somáticas que lhe dêem boa predisposição para o trabalho no campo, que é um trabalho pesado. [...] esse homem não pode ter doença nenhuma [...] em vez de resolver problemas, vão trazer mais problemas ao Idago, não pode trazer contra-indicação dos seus aparelhos locomotores (GOIÁS, 1963a, p. 20-21).

Na estimativa do coronel Petrônio, o Idago estava em condições de levar 200 famílias para Arraias, o primeiro CAU selecionado, contudo, ponderava: "não vamos levar os super-homens [...]. Apenas não queremos levar tuberculose para lá [...] tenho que levar pessoal com nível mental capaz de receber um estágio agrícola compatível com que vai ser dado [...] que eles tenham condições mentais" (GOIÁS, 1963b, p. 57). Os candidatos jovens, mais fortes e sadios, considerados aptos a desempenhar grandes esforços físicos eram selecionados, por apresentarem melhores condições físicas e de saúde, seriam mais produtivos. A família era a base para a ocupação dos CAUs, com modelo padrão: casais jovens com filhos pequenos. Colonos que demonstrassem pouca capacidade física eram dispensados, vistos como sujeitos com baixa disposição para o trabalho, portanto, onerosos para o Combinado (GOIÁS, 1963c, n.p.). Seguindo essa lógica, eram excluídos também os idosos. No entendimento de Bernardo (2009, p. 166), "procura-se evitar a existência de estômagos inúteis, de pessoas que sejam suficientes vivas para alimentar, mas demasiado fracas para trabalhar".

Conforme definido pelo regulamento, dentro da

Ao propor a criação de núcleos coloniais a serem ocupados por trabalhadores, muitos provenientes de regiões de conflito, o governo reforçou o interesse em manter sob controle a força de trabalho e o acesso a terra, ao mesmo tempo em que buscava atenuar os conflitos pela posse da terra desmobilizando a luta camponesa...
Rurópolis era vedada a contratação do trabalho assalariado. Cada família cuidava da sua terra e participava da lavoura, desde o plantio até a colheita. Com isso, garantindo o aumento da produtividade e a redução dos custos com a utilização da força de trabalho da família, valorizando o produto final, sem levar em conta as horas de trabalho no custo dessa produção e o aumento marginal do esforço empreendido, não remunerado. A cooperativa de produção encarregava-se da compra e venda de sementes e adubos para os colonos, e a cooperativa de consumo ocupava-se da comercialização dos gêneros alimentícios, dos medicamentos e roupas. Cada uma dessas despesas era debitada na conta do colono, contudo, a terra, na Rurópolis, era de propriedade do Idago, não podendo ser vendida, subdividida nem transferida. Eram arrendadas aos colonos por 49 anos. Anualmente eles pagavam taxa ao Idago, sendo lhes vetada a venda de seus produtos no mercado externo ao Combinado (GOIÁS, 1963c). De acordo com Martins (1998), o modelo proposto deixava em evidencia que o colono não dispunha do domínio da força de trabalho. Ele não é proprietário de sua própria força de trabalho, pois, não podia vender livremente sua mão de obra. No disciplinamento da força de trabalho, o colono não possuía a liberdade de comercializar seu produto, nem tinha autonomia para o uso da terra para si, nem dispunha de tempo livre em face das inúmeras tarefas realizadas na lida diária. É de se lembrar, todavia, que o colono não era o dono, recebeu um pedaço de terra para plantar, ficando sob as amarras do Combinado e do Idago. Dando mostras que a proposta maurista não levava à emancipação do colono, apenas buscava modificar a forma de exploração, sem alterar as relações de produção.

Outro recurso empregado pelo Idago foi a extensão rural para formar sujeitos aptos a lidar com as técnicas e tecnologias para responder aos novos conhecimentos, práticas de produção, insumos e equipamentos. A intenção era romper com a velha prática do manejo da terra, com processos artesanais e rudimentares, para construir um saber novo, centrado em técnicas racionais exigidas pela modernização da agricultura. Na medida em que se retirava do trabalhador rural/colono a autonomia no processo de trabalho e que se transferiam para o gestor as funções de planejar, organizar, selecionar, treinar/capacitar, avaliar e definir os meios necessários para desenvolver o trabalho em menor tempo e com maior produtividade, o conhecimento empírico da lida diária dava lugar à 
formação dentro dos princípios estabelecidos pelos gestores/tecnocratas das agências estatais e escritórios tecnoempresariais. Isso quer dizer "educação para o trabalho" dentro da lógica do extensionismo rural almejada pelo Idago, que priorizava o ensino das modernas técnicas de plantio e cultivo em detrimento do ensino das letras. Tratava-se de capacitar o trabalhador para bem responder ao processo de modernização da agricultura e também à disciplina. Esse modelo ocorria em uma conjuntura de intensa mobilização no campo e de efervescência das ligas camponesas. Assim, nada foi por acaso. Por meio do extensionismo rural, o Idago desenvolveu uma "ação idealística, as Bandeiras Agrárias" que, na prática, vislumbravam "o elo entre universidade e o meio rural". Por meio delas os universitários/voluntários assumiam o compromisso de levar "ao homem do campo um programa de educação de base visando sua capacitação técnica" capaz de promover "o aumento da produtividade do trabalhador rural" (GOIÁS, 1963b, p. 49). As universidades goianas da época, federal e católica, aderiram à proposta, contribuindo na mobilização dos voluntários e na elaboração do roteiro psicodidático, a Cartilha do Bandeirante Agrário, sob a coordenação Faculdade de Filosofia da Universidade Federal de Goiás. A cartilha pregava o bandeirantismo, com sentido patriótico e de retribuição, apelando para o sentimentalismo dos universitários: "você estudou a custa do homem do campo ignorante, desprotegido e, às vezes explorado. É justo que você pague este favor" (GOIÁS, 1964a, p. 50). Apelava, ainda, para o sentimentalismo cristão - "ame seu irmão do campo" - e prescrevia condutas de comportamento:

entre com tato [...] conte um caso, uma anedota [...] simples [...] faça um favor imediato; mostre interesse pela lavoura e coisas do campo [...] elogie. [...] Não fale como sabichão [...] Conquistada a confiança [...] coloqueos a par de suas intenções: você não é um agitador. Depois, informe-se sobre a possibilidade de se falar ao homem do campo, se há alguma Organização ou Movimento neste sentido e integre-se no contexto local (GOIÁS, 1964a, p. 51).

Na prática, exercitou-se o controle social pela atividade desenvolvida, pois os universitários sendo responsáveis pelo cadastro contendo informações gerais dos elementos visitados: "imaginem que instrumento de pesquisa social não é isso, porque quanto custa uma pesquisa social?", gabava-se o coronel Petrônio (GOIÁS, 1963b, p. 56). Bandeiras Agrárias, por certo, indicaria novas possibilidades de ação para o Idago, e as informações coletadas com a população rural seriam transformadas em cartilha. A missão investia no esclarecimento do homem do campo, ao disseminar regras de comportamento, de conduta moral, e técnicas e habilidades necessárias à modernização da agricultura e de combate à pregação subversiva atendendo às expectativas de desenvolvimento prescritas pelos tecnocratas e pela Igreja. Tal experiência, assistencialista e descontínua, usava da retórica nacionalista para mostrar que sua estratégia pretendia aumentar sua capacidade de ação, ao mesmo tempo em que combatia as ideias consideradas subversivas, ou seja, favoráveis às reformas de base.

\section{Considerações finais}

Não restam dúvidas de que na política agrária implementada pela gestão maurista o cenário no campo pouco se alterou. Resguardou-se a estrutura do latifúndio com agravamento da situação, uma vez que a propriedade se tornou mais concentrada, ou seja, um processo excludente em que apenas uma minoria foi beneficiada e uma ampla maioria marginalizada do processo e dos seus resultados. Esses aspectos foram contestados pelas organizações camponesas em todo o estado, por excluir parcela significativa dos trabalhadores rurais, posseiros e camponeses da reprodução da vida em melhores condições. Assim, eles viram o sonho ir embora. Ao propor a criação de núcleos coloniais a serem ocupados por trabalhadores, muitos provenientes de regiões de conflito, o governo reforçou o interesse em manter sob controle a força de trabalho e o acesso a terra, ao mesmo tempo em que buscava atenuar os conflitos pela posse da terra desmobilizando a luta camponesa, deslegitimando suas formas tradicionais de vida, trabalho e organização, deslocando o eixo da questão fundiária para a ausência de técnica e induzindo o aparecimento de um novo trabalhador rural capaz de responder ao projeto capitalista, aspecto defendido por Mauro Borges, que afirmava: "Não podemos, ter prosperidade rural [...], sem que tenhamos [...] a educação do homem, a tecnologia que deve ser incluída no trabalho e a conduta que deve acompanhá-lo de perto [...] esses fatores: 'terra e homem' darão a resultante ideal a que se destina a Reforma Agrária" (GOIÁS, 1962b, p. 26). Vem daí sua ofensiva em relação ao enfrentamento da questão, com reforço do sentido ideológico da proposta agrária e sua vinculação ao plano maior, identificado com as forças conservadoras de manutenção do latifúndio. $\mathrm{O}$ apelo à tecnização do trabalho propagava um novo modo de vida espelhado nos aspectos da vida urbana, de modernização e desenvolvimentismo, abrindo as portas para o promissor mercado industrial de equipamentos e insumos para a agricultura, iniciante naquele contexto. 
No que tange as diretrizes construídas pelos escritórios de consultoria para as administrações estaduais constituíram as bases do Estatuto da Terra, vigente a partir de 1964, com a ascensão dos militares ao poder. Desta forma, reforçou-se a atuação do estado de Goiás como laboratório das propostas formuladas pelo Ipes para a modernização da agricultura. Tal afirmação é comprovada no documento endereçado por Mauro Borges ao Ministro da Defesa, Costa e Silva, em que o governador reiterava seus propósitos de oferecer "a Goiás e ao Brasil uma estrutura agrária pioneira, com possibilidade de servir, como experiência-piloto, para um programa de colonização, de amplitude nacional" (GOIÁS, 1964b, p. 27).

Apesar de ter apoiado o Golpe de 1964, Mauro Borges teve seu mandato suspenso pela ditadura militar. Seu projeto, como tantos outros, foi descartado para ceder lugar ao novo modelo instaurado pela ditadura. Todavia, constata-se que ambos os modelos fortaleciam a questão social: o aumento da exploração da força de trabalho, com deterioração das condições de vida e trabalho no campo, e o agravamento do êxodo rural. Em Goiás, ao longo da história, assistimos quão é limitada a possibilidade de acesso a terra para os que nela trabalham, todavia, a terra é um negócio de pequena minoria, apoiado pelo Estado, valendo-se de políticas de financimentos de incentivo à mecanização e aumento da produtividade. Esse contexto adverso tem levado os trabalhadores a forjar, na luta coletiva, a resistência diante da exploração e das aviltantes condições de sobrevivência a que são submetidos, demarcando uma luta para além de um pedaço de terra, ou seja, uma luta, sobretudo, contra a opressão imposta pelo capital.

\section{Referências}

BERNARDO, J. Economia dos Conflitos Sociais. São Paulo: Expressão Popular, 2009.

BERTRAN, P. Uma introdução à história econômica do Centro Oeste do Brasil. Goiânia: UCG,1988.

BORGES, B. G. Goiás nos quadros da economia nacional: 1930-1960. Goiânia, UFG, 2005.

BRUNO, R. O Estatuto da Terra: entre a conciliação e o confronto. 1995. Disponível em: http://r1.ufrrj.br/esa/V2/ojs/index.php/esa/ article/download/80/76. Acesso: 12 out.2013.

CAMPOS, I. A Política Tradicional: (1930-1960). In: SOUZA. D. B. (Orgs.). Goiás: sociedade e Estado. Goiânia: Cânone Editorial, p. 12-47, 2009.

CARVAlHO, J. M. de. Mandonismo, Coronelismo, Clientelismo: Uma Discussão Conceitual, v. 40, n. 2, 1997. Disponível em: http://dx.doi.org/10.1590/S0011-52581997000200003. Acesso em 13 dez. 2015.

COELHO, J. B.; BARREIRA, C. C. A. M. Esperança camponesa no Estado de Goiás: a luta pela terra. Educação e mudança. Unievangélica: Anápolis, n. 18 e 19, 2007. Disponível em: http//revistas.unievangelica.edu.br. Acesso em: 8 maio 2011.

DREIFUSS, R A. 1964: a conquista do Estado. Rio de Janeiro: Vozes, 1981.

ESTEVES, C. L. S. Estado e agricultura em Goiás: escritórios privados de consultoria e políticas públicas no Governo Mauro Borges (1961-1964). Universidade Federal Fluminense, Niterói, 2011.

. Homem certo para o lugar certo: colonização, educação rural e tecnização da agricultura dos Combinados Agro-Urbanos de Goiás durante o governo Mauro Borges (1961 - 1964). In: OLINTO, B. A.; OLIVEIRA, M. Mendes da Motta Oséias de. História agrária: propriedade e conflito. Guarapuava: Unicentro, 2008.

GOIÁS. Jornal Goiás. Bandeiras Agrárias. Rio de Janeiro, n. 124, 5 ago. 1964a.

GOIÁS. Ata da reunião do governador com os gestores realizada no dia 18.5.1962a. . Ata da reunião do governador com os gestores realizada no dia 27.11. 1962b.

. Ata da reunião do governador com os gestores realizada no dia 16.4.1963a.

Ata da reunião do governador com os gestores realizada no dia 25.6.1963b.

Estrutura Agrária do Governo Mauro Borges. Instituto de Desenvolvimento Agrário, CERNE: Goiânia, Goiás, $1963 \mathrm{c}$.

Of. 126/64, encaminhado ao Ministro da Guerra, general Arthur da Costa e Silva. Goiânia, 26/5/1964b.

Plano de Desenvolvimento Econômico do Governo Mauro Borges. V. I Análise da Estrutura Econômica do Estado, v. II Diretrizes para 1961-1965. Goiânia: 1961.

MARTINS, J. de S. O Cativeiro da terra. São Paulo: Hucitec, 1998.

. Fronteira: a degradação do outro nos confins do humano. São Paulo: Hucitec, 1997.

LEAL, V. N. Coronelismo, Enxada e Voto. São Paulo: Companhia das Letras, 2012.

PEREIRA, S. L. De fazendeiros a agronegocistas: aspecto do desenvolvimento capitalista em Goiás. Pontifícia Universidade Católica de São Paulo, São Paulo, 2006.

PRADO JR., Caio. A questão agrária no Brasil. São Paulo: Brasiliense, 1979.

SILVA, J. G. da. A modernização dolorosa: estrutura agrária, fronteiras agrícola e trabalhadores rurais no Brasil. Rio de Janeiro: Zahar, 1981.

SOUZA, D. B. 1964 em Goiás: o ovo da serpente. Universidade Federal de Goiás, Goiânia, 1990.

TEIXEIRA, M. B. O Golpe em Goiás: história de uma grande traição. Goiânia: UCG; Vieira, 2006. 


\section{Notas}

1 Criado no governo estadunidense de John Kennedy (1960-1963), consistia em investimentos de fundos públicos direcionados para a América Latina. Na prática, não conseguiu descolar-se do viés ideológico imposto pela Guerra Fria, e as reformas transformaram-se em iniciativas contra o avanço do comunismo no continente.

2 Exemplo típico desse processo ocorreu em Trombas e Formoso, região de terras férteis e devolutas, situada no distrito de Formoso, município de Uruaçu, no estado de Goiás. Lá os camponeses construíram suas casas, cultivaram suas roças e se organizaram em Conselhos de Córrego, transformado posteriormente na Associação de Lavradores de Trombas e Formoso, presidida por José Porfírio. A Associação aglutinava posseiros que compartilhavam áreas banhadas pelos córregos que deram o nome à região: Trombas e Formoso. Com habilidade, soube organizar os camponeses e posseiros conforme especificidades locais, a fim de dinamizar as tarefas e atividades em toda a área. A mobilização, face à conjuntura do momento, viria a ser a estratégia de luta pela posse e propriedade da terra. Talvez tenha sido a experiência mais significativa e mais duradoura cultivada pelos camponeses: uma rede de vizinhos, organizada pelos cursos d'água que recortavam o cerrado em busca do vale do Tocantins, configurou-se em eficiente forma de autogoverno e de articulação política, capaz de responder aos desafios da produção e do escoamento, assim como às demandas cotidianas em defesa de suas lavouras contra grileiros, jagunços e a polícia. Foram esses os momentos mais agudos do conflito, devido ao processo de intervenção dos fazendeiros na tentativa de deslegitimação, por meio de grilagem, da posse das terras. Desse movimento emergiram lideranças de projeção estadual e nacional, como José Porfírio, José Firmino, Geraldo Marques e Nego Casseiro (COELHO; BARREIRA, 2007).

3 O processo de ocupação fundiária de Goiás e, sobretudo, a grande concentração fundiáriaé resultado do descaso do governo imperial pelas áreas interioranas, pela dificuldade de ocorrerem as demarcações legais das sesmarias, pelo isolamento e dispersão da população goiana, pela debilidade dos meios de transporte e comunicação, associados à expansão da pecuária extensiva, enquanto principal atividade econômica (BERTRAN, 1988).

4 Naquela conjuntura, a contratação de assessorias de escritórios técnicos era uma prática utilizada por governos estaduais para a realização de estudos e projetos elaborados sob a ótica do planejamento. Pública, com base nos problemas identificados, apontavam-se soluções para assegurar a modernização.

5 O Ipes era uma entidade anticomunista sofisticada e com pretensões científicas que aglutinavam empresários brasileiros ligados aos interesses do capital internacional, políticos, intelectuais, profissionais liberais e militares. Conforme atesta Dreifuss (1981, p. 164), articulava uma sofisticada campanha política, ideológica e militar, com manipulação de opiniões e guerra psicológica, ao se opor às estruturas populistas, ao executivo nacional-reformista e às forças sociais populares; portanto, "um verdadeiro partido da burguesia".

6 Presidente da Fundação Brasil Central, agência instituída por Getúlio Vargas no Estado Novo, destinada a promover a ocupação das regiões despovoadas do centro-oeste brasileiro, dentro da proposta da Marcha para o Oeste (ESTEVES, 2011).

7 Segundo Esteves (2008), o modelo israelense de cooperativismo, o Kibutz, teve início na década de 1930, com base em um projeto de colonização norte-americana na região. É altamente socializado, tanto na produção quanto no consumo.

\section{Tereza Cristina Favaro}

cristina_gyn@hotmail.com

Doutora em História pela Universidade Federal de Goiás

Assistente Social da Universidade Federal de Goiás

\section{UFG}

Gerência de Ensino e Pesquisa do Hospital das Clínicas - UFG/EBSERH

$1^{a}$ Avenida, $\mathrm{S} / \mathrm{N}-$ Setor Leste Universitário

Goiânia - Goiás - Brasil

CEP: 74605-020 